\title{
Pensamento abissal, educação e movimento negro
}

\section{Maysa Ferreira da Silva*}

O Movimento Negro educador: Saberes construídos nas lutas por emancipação é uma versão atualizada da pesquisa do primeiro pós-doutorado de Nilma Lino Gomes (2017), que ocorreu com a supervisão do Prof. Dr. Boaventura de Souza Santos, que também prefaciou este livro. O estudo foi gerado em um contexto de profundas mudanças econômicas, políticas e na democracia do Estado brasileiro, em confluência com a reorganização do capitalismo nacional e internacional das lutas sociais.

Nilma é a voz de quem fala a partir do conhecer-com, diferentemente de trabalhos que têm sua fala pautada no conhecer-sobre, esta tem construído sua história no chão dos Movimentos Sociais ou mais especificamente do Movimento Negro. É com propriedade que elegeu como tese principal de seus estudos no pós-doutorado o papel do Momento Negro Brasileiro como educador, produtor de saberes emancipatórios e um sistematizador de conhecimentos sobre a questão racial no Brasil. Saberes estes que foram transformados em reivindicações, nos quais vários se tornaram políticas de Estados nas primeiras décadas do século XXI. Na perspectiva da referida é que o livro trata do valor epistemológico das lutas e dos movimentos sociais, em especial o Movimento Negro do Brasil, evidenciando como ator político que educa o próprio momento e como também educa a escola, o Estado e a sociedade. Em um movimento constante, os conhecimentos produzidos intrinsicamente se transformam à medida que se reflete sobre, e historicamente esses conhecimentos têm conquistado um lugar de existência afirmativa no cenário brasileiro.

O livro destaca que desde a década de 1970 o que caracteriza o Movimento Negro em relação aos movimentos sociais e populares é a história. Esse, busca na história, no cotidiano do povo negro brasileiro a chave em prol da superação do racismo, que ocorre no confronto com a história oficial, ou seja, questiona e cria o contraponto com a história posta e propõe a construção de uma nova interpretação da história, desta forma o Movimento Negro se constitui como sujeito que surge da negatividade da história, construindo uma outra possibilidade de entendimento do real.

* Universidade Federal do Paraná. Programa de Pós-Graduação em Educação. Curitiba, Paraná, Brasil. E-mail: mayfsil@hotmail.com. ORCID: https://orcid.org/0000-0003-3089-6322 
O Movimento Negro politiza a ideia de raça e a interpreta como estrutural e estruturante na perspectiva de se compreender a complexidade do quadro de discriminação e desigualdade no Brasil, ou ainda, a interpreta afirmativamente como construção social, rompendo com ideias distorcidas, negativas e naturalizadas sobre raça. Desse modo, coloca em xeque o mito da democracia racial, quebrando formas de resistências das forças conservadoras representadas pelo capital e por grupos privilegiados. Portanto, esse movimento é o mediador na aprovação de políticas de ações afirmativas nas universidades e nos concursos públicos.

A autora analisa algumas concepções teóricas do que é o Movimento Negro, sob a ótica de alguns teóricos (GONÇALVES; SILVA, 2000; DOMINGUES, 2007; PEREIRA, 2008; PINTO, 2013) e destaca que estes variam conforme a base de vinculações disciplinares das quais cada pesquisador é afiliado, considerando o amplo campo das Humanidades. No entanto, salienta que neste estudo a centralidade está na potência do Movimento Negro, ou ainda, nas dimensões mais reveladoras do seu caráter emancipatório, reivindicativo, afirmativo e em especial no campo educacional, em prol da superação do racismo, não se detendo no conceito em si.

Dessa forma, admite o Movimento Negro como um ator coletivo e político, constituído de um conjunto variado de grupos e entidades políticas (e também culturais), das diferentes regiões do país que carregam traços em sua história do período da escravidão, do pós-abolição e do advento da república, povo este que tem seu passado, sua história e a sua cultura desenvolvidos nos contextos de opressão e dominação. E é nessa totalidade que segue persistindo em um ato de resistência com questões para a sociedade, para a educação e para o Estado brasileiro.

Além disso, e considerando todo um processo não linear marcado por avanços, limites e tensões, que ao longo do tempo o Movimento Negro Brasileiro tem produzido saberes e ações de emancipação-regulação educando a si próprio, a escola e o Estado, produzindo novos conhecimentos e entendimentos sobre as relações étnico-raciais e o racismo no Brasil, em conexões com a diáspora africana. A partir da representação por diversas formas de organizações, tais como: impressa; associações de caráter político, informativo recreativo e beneficente; partido político; teatro; fóruns decisivos da política educacional; pesquisas científicas; manifestos públicos organizados; conferências nacionais e mundiais; estrutura do Estado e nas legislações.

Considera-se legítima a atuação do Movimento Negro Brasileiro diante do combate à monocultura racial, pois, ao longo do tempo, a história oficial não reconheceu os conhecimentos de determinados grupos sociais. A população negra, enquanto sujeitos não pertencentes ao grupo hegemônico do poder, foi 
tida como inexistente, assim como toda sua produção, seus conhecimentos e seus saberes. Para analisar essa invisibilidade produzida na hegemonia social brasileira, a obra adota a teoria da sociologia das ausências e das emergências desenvolvida nos estudos de Boaventura de Souza Santos. De modo bem sucinto, pode-se entender a sociologia das ausências como uma alternativa não credível ao que existe, a qual tem por objetivo transformar as ausências em presenças; a sociologia das emergências se relaciona à investigação das alternativas que cabem no horizonte das possibilidades concretas. A pesquisa reflete que é preciso construir uma pedagogia das ausências e das emergências que ajude a valorizar os saberes que resistiram com êxito à dominação epistemológica imposta pelo colonialismo. Processo este analisado a luz do conceito das epistemologias do Sul, que é entendido como o conjunto de intervenções epistemológicas que denunciam a supressão das muitas formas de saber próprias dos povos e/ou nações colonizadas.

A educação como um projeto emancipatório possível e o Movimento Negro um interlocutor entre os saberes do povo negro e os conhecimentos escolares e/ ou científico possibilitam tencionar a estrutura secular da escola, da universidade e da ciência historicamente posta. Estrutura esta caracterizada pelo pensamento abissal, ou seja, pensamento que despreza, desqualifica e separa os saberes e conhecimentos produzidos fora do eixo Norte do mundo.

Uma alternativa ao pensamento abissal apresentada no livro é uma pedagogia pós-abissal, para tanto se faz necessário compreender como se deram as tensões históricas construídas nas relações de poder e conhecimento e que envolvem coletivos sociais e suas práticas, ou ainda, a tensão regulação-emancipação no contexto social.

De forma canônica, a concepção social admite que a regulação social se alicerce em três princípios, a saber: do Estado, do mercado e da comunidade; E a emancipação social ancora-se em três racionalidades: a científica-instrumental, moral prática e estético-expressiva. Entretanto esse modelo entra em crise quando a emancipação que era o outro da regulação assume a dupla função. Por isso urge a necessidade de uma nova forma de emancipação social.

Ancorados no paradigma da modernidade ocidental pode-se na tensão regulação emancipação distinguir o conhecimento-emancipatório e o conhecimento-regulação. Entende-se o primeiro como trajetória entre um estado de ignorância, denominado colonialismo, e um estado de saber, designado solidariedade; e o segundo, a trajetória entre um estado de ignorância, denominado caos, e um estado de saber, designado ordem.

Socialmente, nos últimos tempos, houve um desequilíbrio entre estes conhecimentos em que o conhecimento-regulatório encontrou a primazia sobre o conhecimento-emancipação. Sendo que, a ordem tornou-se hegemônica 
do saber, que está ligada à ciência moderna, à experimentação, à teorização, à sistematização de informações, à tecnologia; e o caos na forma hegemônica da ignorância que está vinculado ao saber, sabor, saborear, à sapiência e ao sábio.

Outro tipo de reflexão epistemológica no campo da educação, desenvolvida no livro, foi pensar sobre conhecimento e saber com o propósito de pensar projetos educativos emancipatórios. A autora chama a atenção para formas de conceber 'conhecimento' e 'saber' que podem levar à hierarquização entre ambas e pode remeter à monocultura do saber, que é oposta à ecologia dos saberes.

A proposta para evitar a hierarquização é que essa reflexão ocorra por meio da pedagogia das ausências e da construção de uma pedagogia pós-abissal, pois por meio destas é possível considerar e incorporar a constelação de saberes/ formulados no mundo de forma geral, e, no caso específico do currículo escolar, este contemplaria de fato a diversidade.

Nesse sentido, o conceito adotado está ancorado nos estudos de Boaventura de Souza Santos, que na letra da obra apresenta-se da seguinte forma:

o conhecimento implica uma trajetória, uma progressão de um ponto ou estado A, designado ignorância, para um ponto ou estado $\mathrm{B}$, designado saber. As formas de conhecimento distinguem-se pelo modo como caracterizam os dois pontos e a trajetória que conduz de um ao outro. Não há, pois, nem ignorância geral e nem saber em geral. Cada forma de conhecimento reconhece-se num tipo de saber que contrapõe um certo tipo de ignorância, a qual, por sua vez, é reconhecida como tal quando em confronto com esse tipo de saber. Todo saber é saber sobre uma ignorância e, vice-versa, toda ignorância é ignorância de um certo saber. (SANTOS, 2002, p. 72).

Considerando a comunidade negra e o Movimento Negro, que estes produzem saberes diferentes dos saberes científicos, isto é fato, no entanto por serem diferentes não perdem a legitimidade e não se tratam de ações intuitivas, mas genuinamente de criação, reprodução e potência.

Em meio a constelação de saberes produzidos pelos negros e negras no Brasil, três deles foram destacados: os saberes identitários, os políticos e os estéticos corpóreos. A escolha desses saberes, pela autora, se deu porque de certa forma acompanham a trajetória histórica dos negros desde os tempos coloniais e apresentam boa visibilidade, não só na educação, mas na sociedade como um todo. Cabe destacar que a organização, apresentada no livro, desses saberes é apenas para efeito didático, pois estão interligados de maneira dinâmica apesar de suas especificidades. 
O Movimento Negro, em especial no contexto das ações afirmativas, politiza o debate da raça e da identidade negra que passaram a ser tematizados em lugares que antes não eram invisibilizados, e que agora passam a fazer parte, por exemplo: autodeclaração em documentos oficiais, na mídia de forma afirmativa, nos estudos que envolvem violência contra a mulher negra e o extermínio na juventude. Dessa forma, o recorte raça/cor passa a ser uma categoria de análise.

Os saberes políticos estão na perspectiva de reeducar as identidades, a relação com a corporeidade e a própria ação política dentro e fora do Movimento Negro. Da mesma forma, a desigualdade racial passa a ser tema nos debates nas universidades, nos órgãos governamentais, sobretudo no Ministério da Educação e nas relações interpessoais. Desse modo, propõe raça como categoria de análise para compreender o machismo, o sexismo, as desigualdades sociais e as reedições do capitalismo nacional e internacional no campo da produção científica.

As políticas de ações afirmativas reeducam os negros e negras na sua relação com o corpo e também reeducam a sociedade brasileira no seu olhar sobre o corpo negro. Como consequência, os jovens negros são mais firmes para realizar debates sobre temas de seu cotidiano. Os saberes corpóreos estéticos denotam uma estreita relação com corporeidade da mulher negra, pois passou a ser compreendida como parte do direito da cidadania.

O debate sobre a corporeidade negra se faz fundamental, pois em virtude do conflito social, vivenciado "na pele", a comunidade negra toma o corpo negro como espaço de expressão identitária, de transgressão e de emancipação para combater a invisibilidade social, e, em específico, no espaço escolar, por exemplo, a não existência ou relega o corpo negro e seus saberes ao lugar da negatividade e da negação. Esse fato consta em diversos estudos, inclusive os realizados pelos pesquisadores acadêmicos que têm como foco os livros didáticos.

Os saberes estéticos-corpóreos abrem espaço para o debate relacionado à monocultura, ecologia do corpo e gosto estético que por tempos foi construído com base no ponto de vista do pensamento da branquidade. Esse saber orienta a criação de novos tipos de relações, de uma nova linguagem e de uma nova ética para reorientar e interpretar a história do Brasil, como também a educação escolar.

A corporeidade negra contemporaneamente vive em um processo contínuo de tensão regulação-emancipação social. $\mathrm{O}$ corpo negro regulado remete ao colonialismo/escravidão e o corpo negro emancipado, à solidariedade/liberdade. Os saberes emancipatórios nacionais carregam consigo uma pesada carga de regulação, que são construídas não só pelo capitalismo, mas também pelo racismo e pelo machismo.

Dessa forma, reafirma o papel fundamental do Movimento Negro, pois é capaz de atuar no desvelar de ações de regulação, propor o saber emancipação 
e tenciona dialeticamente a regulação-emancipação sociorracial no campo das relações raciais e educacionais. Três ações com os seus desdobramentos foram manifestas, no livro, para representar estas tensões sociais, são elas: a abolição da escravatura em 1888, a estética negra e as ações afirmativas.

A obra caminha para o fechamento de seus escritos colocando no palco os movimentos sociais, o Movimento Negro e as subjetividades desestabilizadoras, envoltos pela reflexão para além de interrogações poderosas sobre a ação humana no passado e no presente e destaca que é preciso identificar o sentido de tais interrogações em seu tempo. E estas devem incidir nos traços que remetem à união dos movimentos, ao contrário dos motivos que os distinguem. Portanto, importa centrar nas intersecções e luta contra o racismo, o patriarcado e o capitalismo global, alimentados pelas várias formas de discriminação e pela colonialidade do poder, do ser e do saber.

Destaca-se, nos escritos deste livro, que a escola é um espaço que recebe todos os corpos, cada um com suas peculiaridades, no entanto, ainda tem dificuldade de se libertar da pedagogia tradicional que ocupa lugar hegemônico, parecendo enxergar apenas um tipo de corpo, que certamente não é o corpo negro. Isso, no campo científico, configura-se em uma pedagogia de regulação.

A diversidade de corpos em um espaço escolar está para a pedagogia da diversidade que é emancipatória por reconhecer e destacar outras racionalidades que produzem outros conhecimentos construídos por meio de uma vinculação estreita entre a razão e sentimentos, o desejo, os conflitos, as vivências, as lutas, as práticas sociais e $\mathrm{o}$ ato de aprender.

O reconhecimento do Movimento Negro como produtor, sistematizador e articulador de um pensamento que tende a subverter a teoria educacional e construir a pedagogia das ausências e das emergências, repensar a escola, descolonizar os currículos, abre possibilidades para a construção de uma pedagogia pós-abissal (SANTOS, 2010).

\section{REFERÊNCIAS}

DOMINGUES, P. Movimento negro brasileiro: alguns apontamentos. Tempo, v. 12, n. 23, p. 100-122, 2007.

GOMES, N. L. O movimento negro educador: Saberes construídos nas lutas por emancipação. Petrópolis: Vozes, 2017. 
GONÇALVES, L. A. O.; SILVA, P. B. Movimento negro e educação. Revista Brasileira de Educação, n. 15, p. 134-158, set.-dez. 2000.

PEREIRA, A. M. Trajetórias e perspectivas do movimento negro brasileiro. Belo Horizonte: Nandyala, 2008.

PINTO, R. P. Movimento negro em São Paulo: luta e identidade. Ponta Grossa: UEPG; Fundação Carlos Chagas, 2013.

SANTOS, B. S. A crítica da razão indolente: contra o desperdício da experiência. Porto: Afrontamento, 2002.

SANTOS, B. S. Para além do pensamento abissal: das linhas globais a uma ecologia dos saberes. In: SANTOS, B. S.; MENEZES, M. P. (Org.). Epistemologias do Sul. São Paulo: Cortez, 2010. p. 31-83.

Texto recebido em 22 de fevereiro de 2018.

Texto aprovado em 27 fevereiro de 2018. 
